\title{
Trabalho e poder de agir
}

\author{
CLOT, Yves. Tradução de Guilherme João Freitas Teixeira e Marlene Machado Zica Vianna. Belo Horizonte: Fa- \\ breFactum, 2010. 368p. ISBN: 978-85-63299-08-6
}

Trabalho e poder de agir é a segunda obra completa de Yves Clot publicada no Brasil ${ }^{1}$. Ela se encontra em uma linha de continuidade com A função psicológica do trabalho (CLOT, Yves. Petrópolis: Vozes, 2006) ao propor um aprofundamento de questões tratadas naquele momento, mas representa, ao mesmo tempo, um avanço por expor de forma mais ampla o campo da Clínica da Atividade. Assim, ela se inicia pela apresentação das origens da disciplina, para, em seguida, expor seu corpo conceitual e os métodos que vem desenvolvendo. Trata-se de uma leitura essencial para todos os interessados por esse campo do conhecimento, não apenas pela sua abrangência, mas também pela profundidade com a qual o autor trata de temas que permitem uma melhor compreensão a respeito dos rumos que vem tomando e do alcance que seus avanços permitem.

Na introdução, Clot trata de alguns aspectos essenciais para a melhor apreensão dos temas que virão a seguir, dentre eles, a maneira como concebe a atividade, sobretudo nas suas relações com as emoções, com as cognições e com a afetividade em geral. Essas considerações iniciais culminam no tratamento do que chama de "poder de agir", conceito que ocupa um lugar cada vez mais central na sua disciplina.

A primeira parte da obra é composta de quatro ensaios de difícil acesso, apesar de sua relevância, uma vez que apresentam os teóricos que serviram de base para a construção da Clínica da Atividade: A. Wisner, L. Vygotsky, L. Le Guillant e I. Oddone. Todos eles estão na origem de alguma disciplina ou de uma prática inovadora no seu campo de atuação, sendo o primeiro associado à Ergonomia Francesa, o segundo, à Psicologia Sócio-histórica, o terceiro à Psicopatologia do Trabalho e o quarto, ao "modelo operário italiano", uma importante inovação cuja essência consiste em transformar a prática do psicólogo nos contextos laborais.

A Ergonomia Francesa, disciplina inseparável da trajetória de A. Wisner, é posta por Clot como "ponto de partida” para seu próprio percurso devido a vários aspectos: por representar um antídoto ao positivismo ao propor o exercício ergonômico determinado por ques- tões vindas do campo; por colocar saúde e atividade como sinônimos; por se configurar como uma fuga ao dogmatismo, encorajando constantemente a discussão; e, finalmente, pela clara consciência dos seus limites, ao se propor o alcance de objetivos bem mais modestos e, por isso mesmo, mais factíveis.

Vygotsky é apresentado ao leitor como uma das principais fontes de inspiração da Clínica da Atividade, sendo sua obra apropriada de maneira inteligente e criativa por essa disciplina. No ensaio a ele consagrado, Clot trata de alguns aspectos centrais, dentre eles, o tratamento oferecido pelo psicólogo russo ao problema da deficiência, além das questões relativas aos afetos e aos processos de desenvolvimento. Tudo isso sem omitir a crítica ao tratamento caricatural que vem sendo dado ao seu legado, visto frequentemente como uma espécie de “ortopedia cognitiva”. Mas o essencial encontra-se na maneira pela qual nosso autor expõe a concepção vygotskiana de Psicologia, isto é, como um método de ação e não de conhecimento. Ao avançar na leitura do livro, fica patente ao leitor a relevância dessa contribuição para a Clínica da Atividade, uma disciplina que vem progressivamente se voltando para o desenvolvimento de instrumentos suscetíveis de ampliar o poder de agir do homem no trabalho.

A contribuição de Louis Le Guillant, psiquiatra francês que produziu o essencial de sua obra durante os anos 50 e 60 do século XX, é também apresentada como um dos pilares que permitiram a edificação da clínica da atividade. $\mathrm{O}$ ensaio que trata desse teórico traz uma síntese preciosa de suas reflexões, tratando, dentre outros aspectos, da questão do ressentimento - tão bem elucidada no seu estudo a respeito das "incidências psicopatológicas da condição da empregada doméstica"-, além das chamadas "doenças da produtividade” e das críticas que dirigiu à psiquiatria de sua época. ${ }^{2}$ Clot ressalta também a visão de Le Guillant a respeito dos impactos do trabalho no psiquismo, ressaltando a presença, em toda sua obra, de uma clínica atenta às condições sociais. Mas o reconhecimento da importância desse teórico não o impede de expor suas insuficiências ao questionar sua adesão, aparentemente pouco crítica, à perspectiva pavloviana, além de apontar para

\footnotetext{
1 Título original: CLOT, Yves. Travail et pouvoir d'agir. Paris: PUF, 2008. 312p.

${ }^{2}$ Alguns dos estudos realizados pelo autor foram publicados no Brasil, em 2006, pela Editora Vozes, na coletânea intitulada "Escritos de Louis Le Guillant - da Ergoterapia à Psicopatologia do Trabalho", contando, inclusive, com um prefácio escrito por Yves Clot.
} 
uma lacuna importante na sua obra: a ausência de uma teorização a respeito da noção de atividade. Ele deixa claro, no entanto, que discorda daqueles que atribuem a Le Guillant uma concepção sociogenética a respeito da doença mental, argumentando, com razão, que tal visão só pode ser fruto de uma interpretação equivocada do seu trabalho.

O quarto e último ensaio dessa primeira parte dedica-se a Ivar Oddone, posto igualmente como um dos pilares da Clínica da Atividade. A forte influência do "movimento operário italiano" em vários países ocidentais já é sobejamente conhecida, sendo que Y. Clot pode ser considerado como o teórico que realizou uma das mais interessantes apropriações desse legado. Em consonância com as discussões que vem trazendo em algumas de suas obras mais recentes, ele concorda com as objeções feitas por Oddone à "simples denúncia das condições inaceitáveis de trabalho" (p. 84), afirmando que o importante é o apoio oferecido aos coletivos de trabalhadores no sentido de manter e, sobretudo, "ampliar seu raio de ação”. Para isso, propõe contribuir para a construção de uma nova forma de se praticar a psicologia nos contextos de trabalho, deixando clara a necessidade de se inventar e reinventar os instrumentos dessa ação. Dedicou-se, então, à criação de dispositivos de diagnóstico e intervenção nos contextos de trabalho, tornando-se uma das principais fontes de inspiração para Clot no desenvolvimento dos seus próprios instrumentos no campo da Clínica da Atividade. A base de sua proposta consiste na criação de "grupos operários homogêneos" nos quais o trabalhador é "protagonista da pesquisa", avaliando os riscos e validando as soluções propostas. Ao fazer isso, Oddone ultrapassou o mero diagnóstico, propondo um dispositivo suscetível de levar os trabalhadores a "pensar coletivamente o trabalho para reorganizá-lo”.

Para Clot, a grande contribuição da perspectiva inaugurada por Oddone consiste na possibilidade que ela comporta de mudar nosso olhar em torno da experiência operária, que deixa de ser apenas reconhecida para ser objeto de transformação. É nela que se apóia para criticar as práticas dos experts, bastante frequentes nos dias atuais, ou seja, aqueles profissionais que se encarregam de diagnosticar e combater a nocividade das condições de trabalho sem uma participação efetiva dos trabalhadores. Mas reconhece também que Oddone foi o primeiro a tratar da função psicológica do coletivo de trabalho, identificando nesse coletivo a fonte na qual "a atividade individual encontra seus recursos". Sendo assim, percebeu, na sua perda ou no seu enfraquecimento, a origem da maior parte das provações sofridas no mundo do trabalho. Foi graças a essa descoberta, diz ele, que pôde desenvolver suas próprias reflexões a respeito do papel do coletivo de trabalhadores na atividade individual, um dos pontos centrais de sua disciplina.

Os principais conceitos que vêm sendo desenvolvidos no âmbito da Clínica da Atividade estão expostos na segunda parte da obra, composta por quatro capítu- los. O primeiro deles, intitulado "Clínica da atividade e psicopatologia do trabalho", é um dos ensaios mais importantes da coletânea. Nele, aparecem diversos problemas tratados pela Clínica da Atividade, mas, desta vez, com a preocupação de mostrar a forma pela qual se articulam com o campo da Saúde Mental e Trabalho. Para isso, Clot toma como ponto de partida os estudos realizados por L. Le Guillant em torno dos condutores de trem, mas vai além ao tratar dos conceitos de atividade realizada, real da atividade, catacreses objetivas e subjetivas, além de expor sua concepção de saúde, defesas e poder de agir. É nesse ensaio também que evidencia a contribuição de G. Canguilhem para o desenvolvimento do seu pensamento, em especial no que concerne às reflexões que o médico e filósofo francês propôs em torno de normalidade, doença e saúde.

Nos capítulos subsequentes, Clot aprofunda alguns dos conceitos já expostos anteriormente de maneira pontual: o gênero profissional, os estilos de ação, o gesto e o indivíduo na sua relação com o coletivo. Em um dos artigos, intitulado "Gêneros profissionais e estilos de ação”, já se percebe uma antecipação de aspectos importantes relativos a problemas metodológicos, que só serão tratados de forma mais detalhada na última parte da obra. Ele reafirma que a finalidade maior da Clínica da Atividade consiste na transformação das situações de trabalho, mas sempre preocupado em delimitar os verdadeiros protagonistas dessas mudanças. Ao fazê-lo, deixa claro, mais uma vez, seu distanciamento do que qualifica como "estratégias clássicas de intervenção" nos locais de trabalho e que culminam geralmente em preconizações resultantes de uma expertise externa. A abordagem proposta pela Clínica da Atividade, diz ele, propõe que se coloque em prática "um dispositivo metodológico destinado a tornar-se um instrumento para a ação dos próprios coletivos de trabalho” (p. 88).

Assim, um aspecto fica evidente em vários momentos da leitura dos ensaios que compõem a obra e por isso merece ser aqui ressaltado: nosso autor só admite como duradouras as transformações que resultam da ação dos próprios trabalhadores e é por essa razão que sua proposta de análise do trabalho preocupa-se em oferecer um amparo aos coletivos de modo a aumentar seu poder de agir e ampliar seu raio de ação no meio profissional. Esse é também o motivo pelo qual ele tem concentrado o essencial dos seus esforços nas questões metodológicas, acreditando que a Clínica da Atividade deve levar à busca de "instrumentos práticos e teóricos” que permitam "alimentar ou restabelecer o poder de agir de um coletivo profissional no seu meio de trabalho e de vida" (p. 98). Foi por isso também que decidiu dedicar a terceira e última parte da obra ao tratamento das questões metodológicas, sobretudo naquilo que diz respeito às possibilidades de ação e à produção do conhecimento, evidenciando mais uma vez que a motivação maior dessa publicação consiste em propor instrumentos de transformação dos contextos de trabalho. Ele oferece, então, ao leitor uma exposição cuidadosa da instrução ao sósia e da autoconfrontação cruzada, 
dois dos principais métodos que vêm sendo adotados e desenvolvidos por sua equipe no Conservatoire National des Arts et Métiers (CNAM). Assim, nos quatro capítulos que compõem essa parte, ilustra com detalhes o uso que tem sido feito desses instrumentos, possibilitando também uma avaliação de sua eficácia.

Na conclusão da obra, um dos aspectos centrais tratados por Clot concerne aos possíveis usos do termo "ofício" no âmbito da Psicologia do Trabalho. Como esse termo tem persistido no vocabulário cotidiano dos trabalhadores franceses, ele decidiu buscar suas raízes etimológicas, concluindo que seu uso atual não pode ser remetido ao sentido a ele atribuído pelos operários do período pré-taylorista ou mesmo pelas corporações artesanais, embora considere que sua permanência em um contexto tão diferente daquele que o originou ultrapasse o simples efeito de uma espécie de "inércia" da linguagem. Assim, percebe que as atividades de serviço - cada vez mais numerosas -, poderiam ajudar a compreender essa persistência do termo, uma vez que dificultam a separação entre trabalho e pensamento. Nesse contexto, continua ele, ocorre a imposição de "uma responsabilidade renovada quanto ao ‘objeto' e, por isso, a definição das tarefas é influenciada, mais do que em outras circunstâncias, por avaliações conflitantes” (p. 282). Além disso, é no setor de serviços que o "objeto" de trabalho se torna "sujeito", acarretando problemas de consciência e colocando no seu centro as questões relativas às finalidades assim como à qualidade daquilo que se realiza, levando o sujeito a enfrentar dilemas relativos ao "justo" e ao "injusto", ao "verdadeiro" e ao "falso" ou mesmo entre o "bem" e o "mal". Todos esses elementos que compõem a atividade é que, segundo nosso autor, parecem ter feito ressurgir o termo "ofício" "na linguagem dos profissionais dos serviços".

No entanto, ele não deixa de reconhecer também certa "inflação" no uso do termo "ofício" em outros setores, tornando necessário compreender melhor as razões pelas quais "seu sentido psicológico parece se ampliar enquanto seu significado sociológico parece se apagar" (p. 283). A busca por uma resposta a essa questão o levou a desenvolver uma importante discussão em torno do problema do reconhecimento, estabelecendo um debate com a Psicodinâmica do Trabalho. Coerente com sua proposta de trazer a controvérsia para o espaço público, ele não se furtou a tal debate, trazendo uma perspectiva diferente para se pensar o problema. Esta consiste em retirar o foco do reconhecimento da hierarquia ou dos pares, conforme preconiza a Psicodinâmica do Trabalho, passando a focalizar a impossibilidade em que muitos se encontram hoje de se reconhecerem naquilo que fazem. Ou seja, segundo ele, é pelo fato de não mais se reconhecerem no ofício que realizam que muitos profissionais "solicitam, de forma tão maciça, 'ser reconhecidos" (p. 286). E mais do que isso, ao se voltarem para a hierarquia buscando uma “reparação imaginária”, na verdade, esses profissionais estão denunciando algo que, infelizmente, está muito comum nos contextos contemporâneos de trabalho: o enfraquecimento do coletivo de trabalho, agora reduzido a "uma reunião de indivíduos expostos ao isolamento” (p. 287). Dessa forma, o reconhecimento pelo outro pode "se tornar uma compensação factícia exatamente no lugar em que havia desaparecido a possibilidade de se reconhecer em algo" (p. 300). É isso que o permite concluir que a demanda insistente pelo reconhecimento do outro ocorre entre aqueles que se encontram impedidos de se reconhecer naquilo que fazem, isto é, aqueles que veem seu ofício sendo maltratado.

Nenhuma disciplina esgota seu objeto nem está isenta de lacunas e a Clínica da Atividade não foge a essa regra. Sendo assim, ao finalizar a leitura de "Trabalho e poder de agir”, o leitor provavelmente terá muitas questões ainda sem respostas. Mas é bastante improvável que isso o impeça de constatar o crescimento considerável dessa disciplina no decorrer dos últimos anos. Os textos criteriosamente escolhido por Y. Clot para compor essa coletânea revelam não apenas esse crescimento, mas permitem antever novos e promissores desdobramentos para um campo que necessita cada vez mais de teóricos com essa capacidade de identificar no trabalho possibilidades de desenvolvimento e de ampliação do poder de agir dos indivíduos.

Maria Elizabeth Antunes Lima

Professora Associada do Departamento de Psicologia da Universidade Federal de Minas Gerais.

E-mail:

antuneslima15@gmail.com 